\title{
Dual Band and Beam-Steering Antennas Using Reconfigurable Feed on Sierpinski Structure
}

\author{
Seonghun Kang and Chang Won Jung \\ Graduate School of NID Fusion Technology, Seoul National University of Science and Technology, 232 Gongneung-ro, Nowon-gu, \\ Seoul 139-743, Republic of Korea
}

Correspondence should be addressed to Chang Won Jung; changwoj@snut.ac.kr

Received 16 June 2015; Revised 21 August 2015; Accepted 6 September 2015

Academic Editor: Ahmed T. Mobashsher

Copyright (C) 2015 S. Kang and C. W. Jung. This is an open access article distributed under the Creative Commons Attribution License, which permits unrestricted use, distribution, and reproduction in any medium, provided the original work is properly cited.

Fractal patch antennas based on the Sierpinski structure are studied in this paper. The antennas operate at dual bands (around 2 and $5 \mathrm{GHz}$ ) and are designed to steer the beam directions at around $5 \mathrm{GHz}$ band (the first harmonic). The antennas use reconfigurable triple feeds on the same antenna plane to have three beam directions. The same scale factor defines the geometrical self-similarity of the Sierpinski fractal. The proposed antennas are fabricated through three iterations from 1st order to 3rd order and utilize FR-4 $\left(\varepsilon_{r}=4.4\right)$ for the microwave substrate. The performances of the antennas, such as reflection coefficients and radiation patterns are verified by simulation and measurement. The results show that the properties of the proposed antennas in three orders are similar.

\section{Introduction}

Fractal-shaped antennas have already been proved to have some unique characteristics that are linked to the geometrical properties of fractals $[1,2]$. Additionally, reconfigurable antennas are leading the current antenna research for wireless communication applications $[3,4]$. The reconfigurable capability enables that single antenna performs equal function with multiple antennas. As thoroughly discussed in [5-13], the self-similarity property of fractals makes them suitable for the design of multifrequency antennas. Sierpinski gasket structures have been credited for their log-periodic behavior in a single antenna element [6]. Because these structures are made by a repeated process, they can produce a wide surface area in a limited space [14]. In this type of iterative procedure of the Sierpinski structure, an initial structure, the so-called generator, is replicated many times at different scales, positions, and directions to grow the final fractal structure. The current distribution on the Sierpinski structure shows that most of the current density concentrates on the joints and edges of the different triangle clusters that make up the structure [15]. Because the Sierpinski structure is widely studied as a standard fractal structure, it is easy to utilize in applications.
The idea of this paper is to use simple symmetrical structures to offer the possibility of multifrequency band and beam tilt by using three feeding points. The beam-steering capability of the proposed antennas is achieved by changing location of the feeding points without using particular RF switches. Therefore, this paper focuses on a Sierpinski shaped patch antenna, offering the possibility to adjust its main beam in three directions by using three different feed points in one structure [16]. A Sierpinski fractal is used for the design of a dual band beam-steering antenna. In order to compare differences, the Sierpinski structures from 1st order to 3rd order are designed. The proposed antennas operate at around $2 \mathrm{GHz}$ and $5 \mathrm{GHz}$ bands and use the geometrical symmetry of the Sierpinski structure to redirect the beam. In communication systems, these antennas are utilized in various MIMO applications and adaptive beam-steering with high directivity and low correlation by using beam-steering characteristics $[17,18]$.

\section{Antenna Design}

2.1. Antenna Geometry. The fractal antenna with Sierpinski structure is chosen for its simple configuration and 


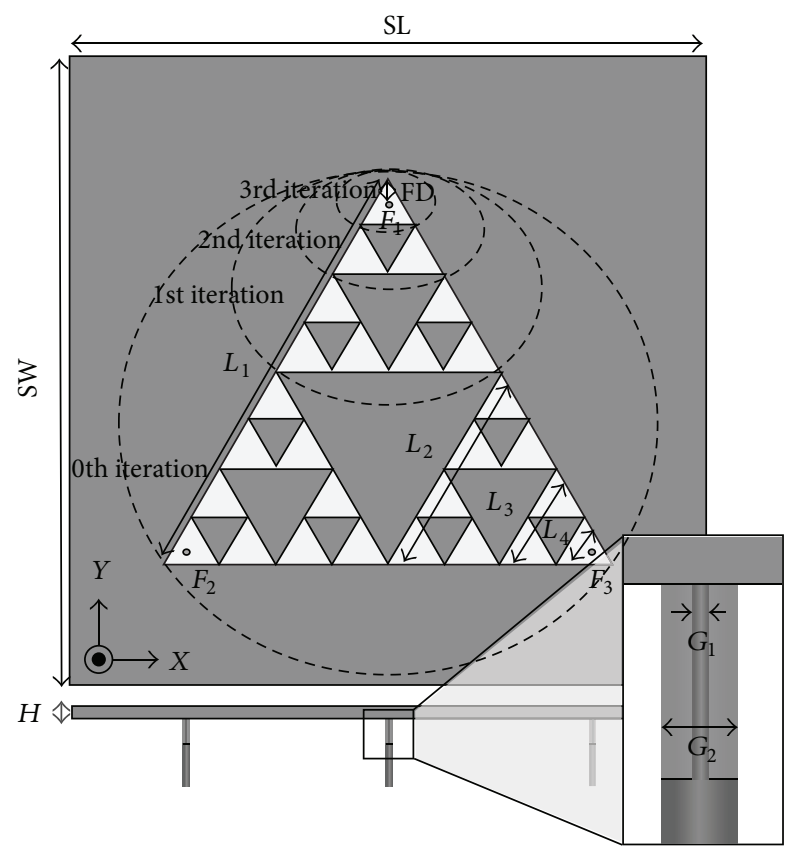

FIGURE 1: Configuration of the proposed antenna.

advantage in multifrequency. The Sierpinski structure has been generated through three iterations using the subtraction. Firstly, draw an equilateral triangle (0th iteration). Secondly, generate an inner triangle (1st iteration) by connecting the midpoints of the three sides of a triangle. Thirdly, subtract the inner triangle from the equilateral triangle. Then, the 1storder structure is obtained. By repeating the same process with each of the remaining smaller triangles, 2nd-order and 3rd-order structures are obtained. The configuration of the proposed antenna is shown in Figure 1. With this shape, a multiband feature can be obtained. The goal of this study is to design a dual band and beam-steering antenna. This antenna was fabricated on a FR-4 substrate with relative permittivity of 4.4 and loss tangent of 0.02 . The triangle Sierpinski structure part and ground were manufactured with copper. The ground was located in the bottom plane. The size of the substrate was $100 \mathrm{~mm}(\mathrm{SL}) \times 100 \mathrm{~mm}(\mathrm{SW})$, and its thickness was $1.6 \mathrm{~mm}(H)$. The distance from the feed to a vertex was $3.75 \mathrm{~mm}$ (FD). The antennas were fed through three feeding points $\left(F_{1}, F_{2}\right.$, and $\left.F_{3}\right)$ with coaxial cables. In practical applications, a $50-\Omega$ coaxial cable can be used as a feeder. The diameter of the inner coaxial cable was $1 \mathrm{~mm}$ $\left(G_{1}\right)$ and that of outer one was $3.8 \mathrm{~mm}\left(G_{2}\right)$, respectively. One of the coaxial cables was used to excite the antenna. At the first resonance of the antenna, the antenna radiation pattern is similar to that of a normal patch antenna. However, at the second resonance (the first harmonic), the antenna radiation pattern has two different directions which are tilted and depended on the feeding location. The detailed dimensions of the proposed antenna are summarized in Table 1.

2.2. Antenna Simulation. The proposed antennas are simulated using HFSS simulation software. The simulated
TABLE 1: Detailed dimensions of the proposed antenna (unit: $\mathrm{mm}$ ).

\begin{tabular}{lcccccccccc}
\hline Parameter & SL & SW & FD & $H$ & $L_{1}$ & $L_{2}$ & $L_{3}$ & $L_{4}$ & $G_{1}$ & $G_{2}$ \\
\hline Value & 100 & 100 & 3.75 & 1.6 & 71 & 35.4 & 17.6 & 8.75 & 1 & 3.8 \\
\hline
\end{tabular}

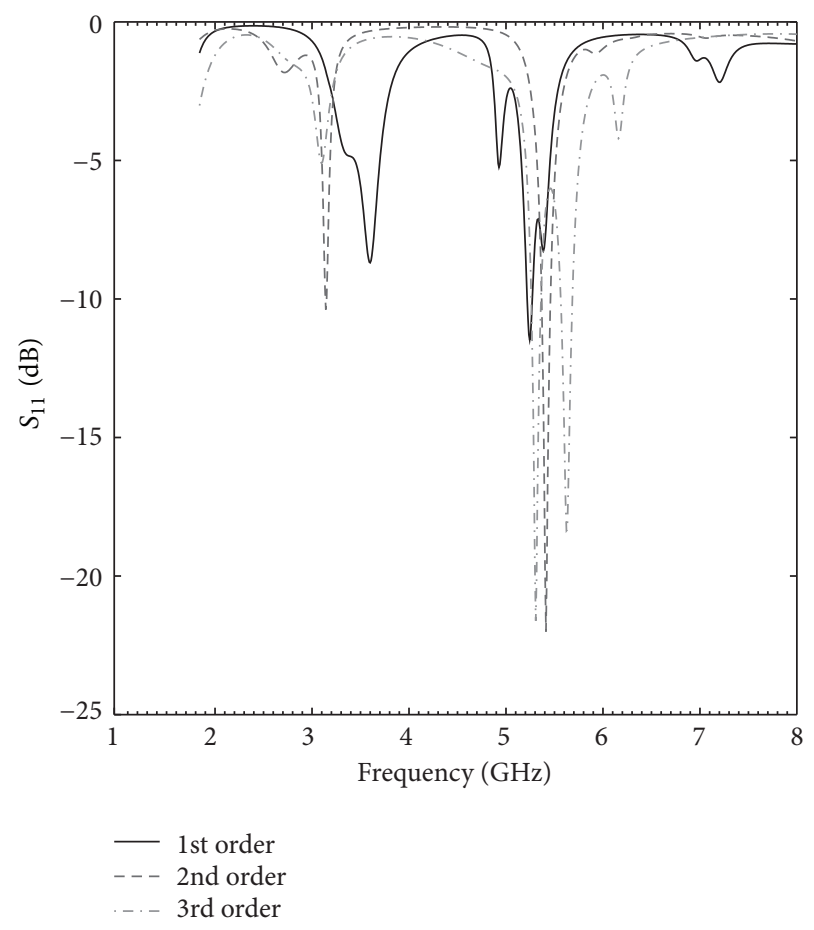

FIGURE 2: Simulated reflection coefficients $\left(S_{11}\right)$ of the proposed antennas.

reflection coefficients of the proposed antennas are shown in Figure 2. As can be seen, the simulated reflection coefficients were under $-6 \mathrm{~dB}(\mathrm{VSWR}<3)$ at an operation frequency band. The simulated operation bandwidths of the 1st order are 2.89-3.09 GHz and 4.79-5.09 GHz, those of the 2nd order are 2.44-2.52 GHz and 4.97-5.16 GHz, and those of the 3rd order are 2.39-2.47 GHz and 4.84-5.42 GHz. This figure shows that antennas in three orders (1st, 2nd, and 3rd) have similar resonant frequencies to a dual band. Figure 3 shows the threedimensional radiation patterns of the proposed antennas. The simulated radiation patterns at the first resonant frequencies, specified at $3 \mathrm{GHz}, 2.48 \mathrm{GHz}$, and $2.43 \mathrm{GHz}$ for three orders, respectively, do not tilt and radiate toward $z$-axis as a normal patch antenna. In contrast, the beam-steering characteristics of these proposed antennas are clearly seen at the second resonant frequencies, namely, $5.03 \mathrm{GHz}, 5.06 \mathrm{GHz}$, and $5.3 \mathrm{GHz}$ in three orders, respectively. Because the antennas have symmetrical feed structures, the maximum beam directions of the radiation patterns clearly change according to three feeding points $\left(F_{1}, F_{2}\right.$, and $\left.F_{3}\right)$. The detailed performances of the simulated antennas are summarized in Table 2.

\section{Measurement Results of the Antenna}

Figure 4 shows the fabricated antennas at three orders. Figure 5 shows measurement process of radiation patterns in 


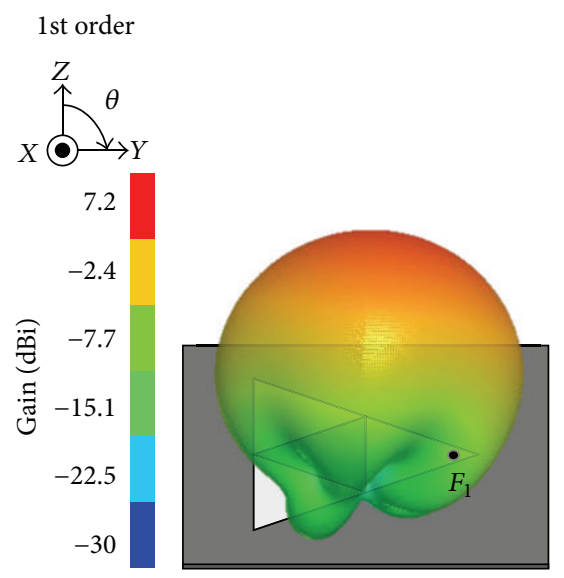

Feeding point 1
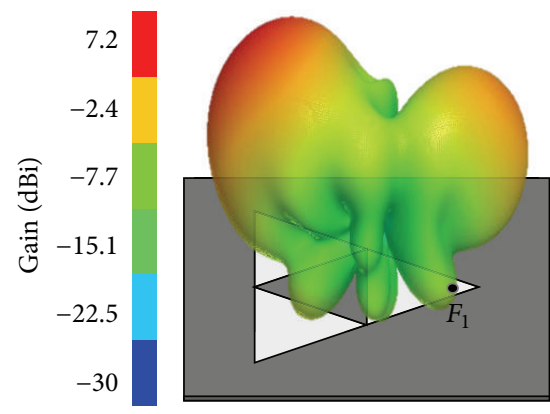

Feeding point 1

2nd order

个 $\theta$

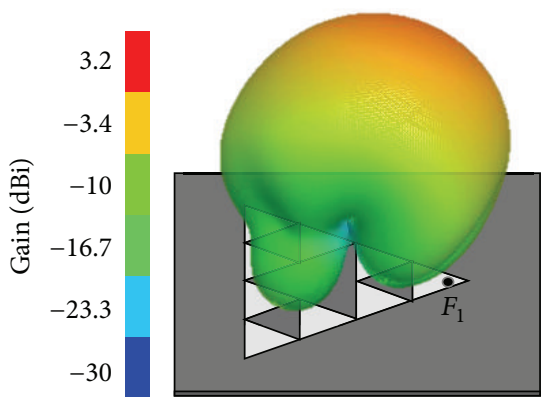

Feeding point 1

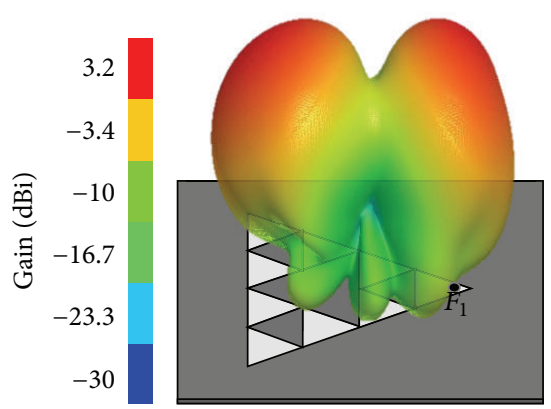

Feeding point 1

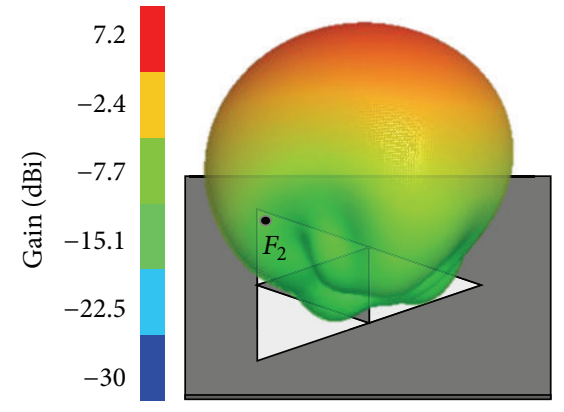

Feeding point 2

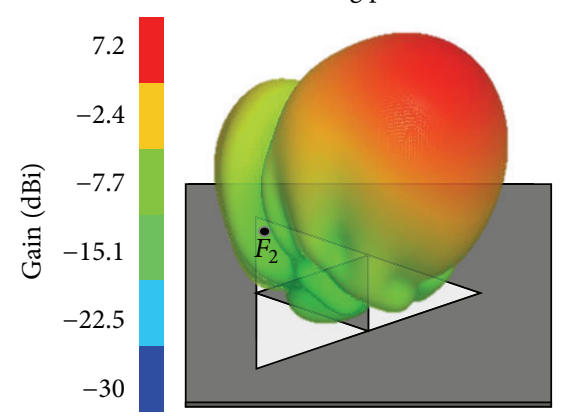

Feeding point 2

(a)

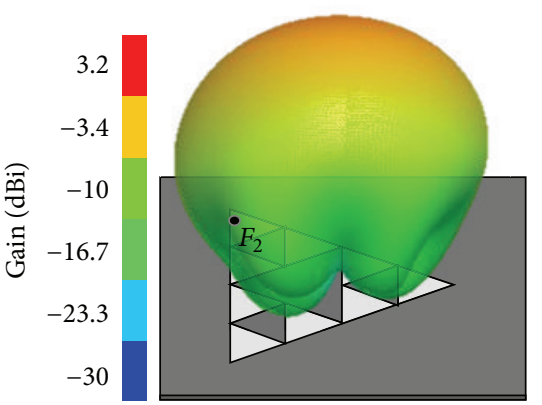

Feeding point 2

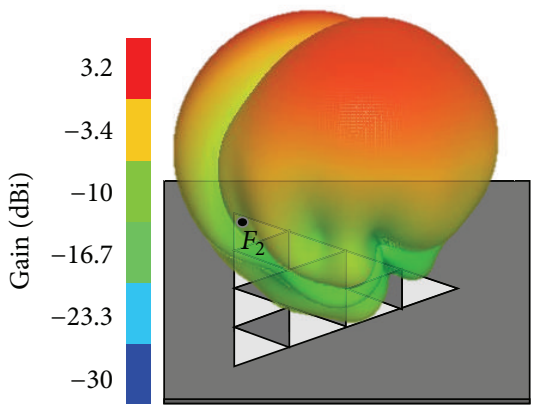

Feeding point 2

(b)

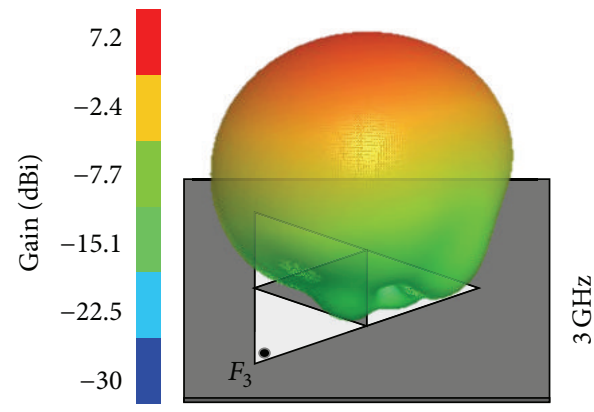

Feeding point 3

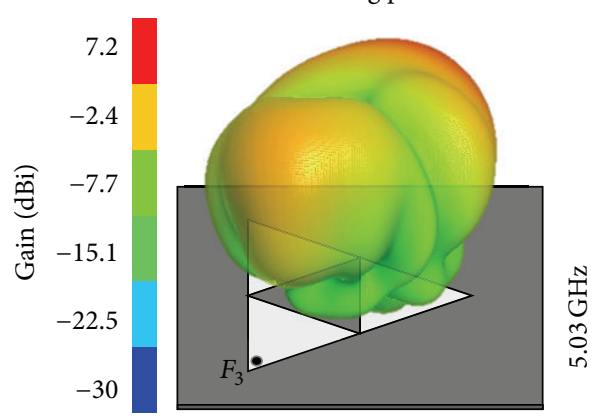

Feeding point 3
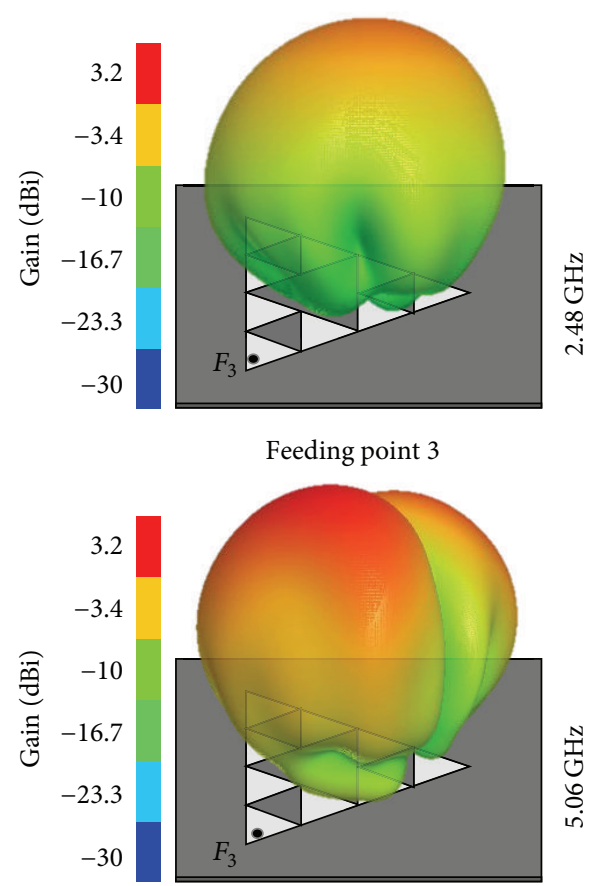

Feeding point 3

FIGUre 3: Continued. 

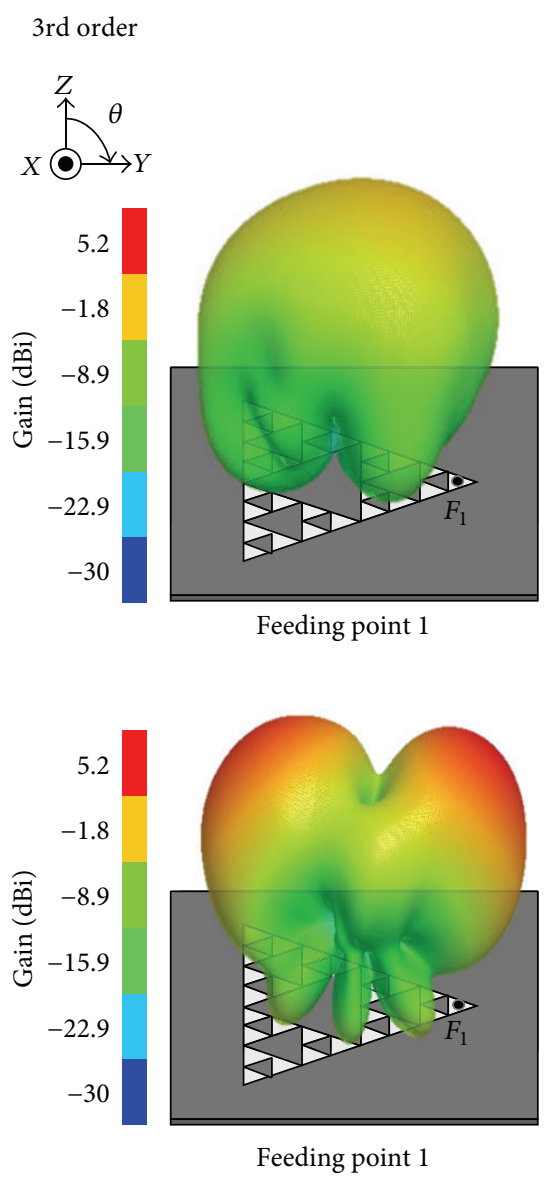

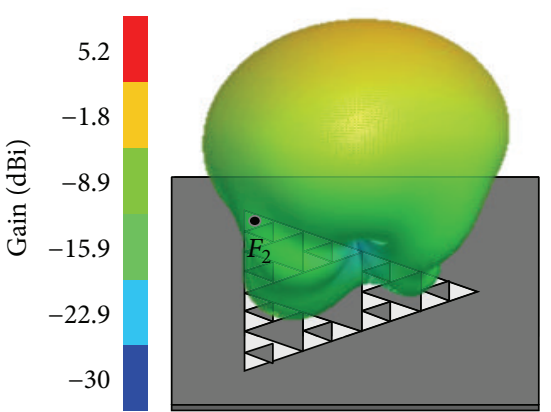

Feeding point 2

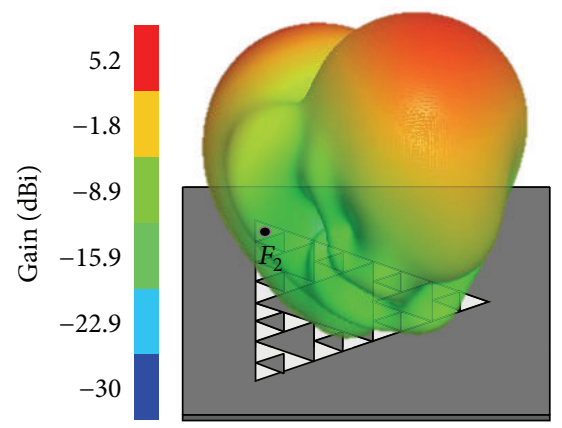

Feeding point 2

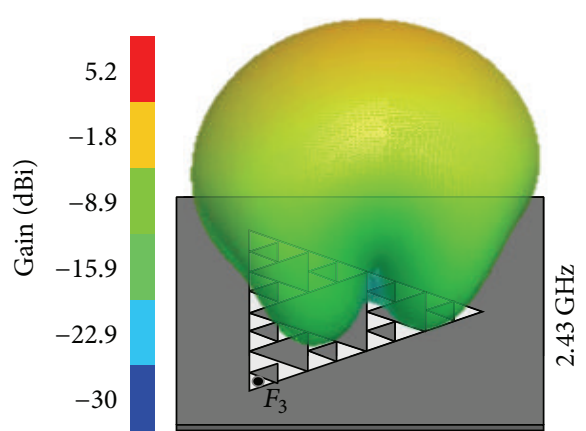

Feeding point 3

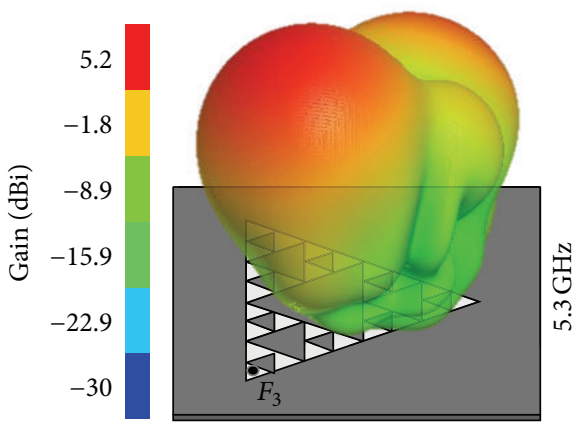

Feeding point 3

(c)

Figure 3: Simulated 3D radiation patterns of the proposed antennas: (a) 1st order, (b) 2nd order, and (c) 3rd order.

TABLE 2: Summary of the simulated antennas' performances.

\begin{tabular}{|c|c|c|c|c|c|}
\hline \multirow{2}{*}{ Order } & \multirow{2}{*}{ Resonant frequency } & \multicolumn{2}{|c|}{ Maximum beam direction $\left(^{\circ}\right)$} & \multirow{2}{*}{$\mathrm{HPBW}\left(\left(^{\circ}\right)\right.$} & \multirow{2}{*}{ Peak gain $(\mathrm{dBi})$} \\
\hline & & $\theta$ & $\emptyset$ & & \\
\hline \multirow{2}{*}{ 1st order } & $3 \mathrm{GHz}$ & - & - & 71 & 4.78 \\
\hline & $5.03 \mathrm{GHz}$ & $-41,55$ & 274 & (L) $44,(\mathrm{R}) 48$ & 7.16 \\
\hline \multirow{2}{*}{ 2nd order } & $2.48 \mathrm{GHz}$ & - & - & 69 & 1.07 \\
\hline & $5.06 \mathrm{GHz}$ & $-38,30$ & 51 & (L) 50, (R) 33 & 3.2 \\
\hline \multirow{2}{*}{ 3rd order } & $2.43 \mathrm{GHz}$ & - & - & 75 & 3.41 \\
\hline & $5.3 \mathrm{GHz}$ & $-34,44$ & 89 & (L) 50, (R) 39 & 5.19 \\
\hline
\end{tabular}

an anechoic chamber. The measured reflection coefficients of the proposed antenna at three orders are shown in Figure 6. All the reflection coefficients were under $-6 \mathrm{~dB}$ (VSWR $<3$ ) at an operation frequency band. The measured operation bandwidths of the 1st order are $2.89-3.1 \mathrm{GHz}$ and $4.64-5.3 \mathrm{GHz}$, those of the 2 nd order are $2.4-2.5 \mathrm{GHz}$ and $5.09-5.3 \mathrm{GHz}$, and those of the 3rd order are 2.362.47 GHz and 4.88-5.44 GHz. Figure 7 shows the measured two-dimensional radiation patterns of the three cases at three orders, namely, radiation pattern at the first resonant frequency with half power beam width (HPBW) at $\emptyset=90^{\circ}$, radiation pattern at the second resonant frequency with left half power beam width (LHPBW), right half power beam width (RHPBW), with maximum beam directions at $\emptyset=90^{\circ}$, and radiation pattern at the second resonant frequency with maximum beam directions at $\theta=90^{\circ}$. The maximum beam directions of the radiation patterns were changed by three orders (1st, 2nd, and 3rd). The maximum beam directions 


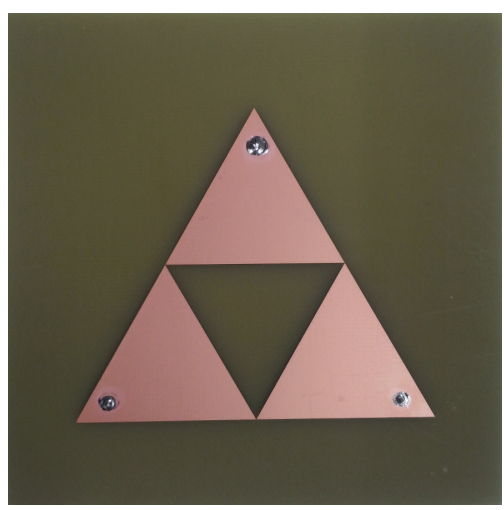

(a)

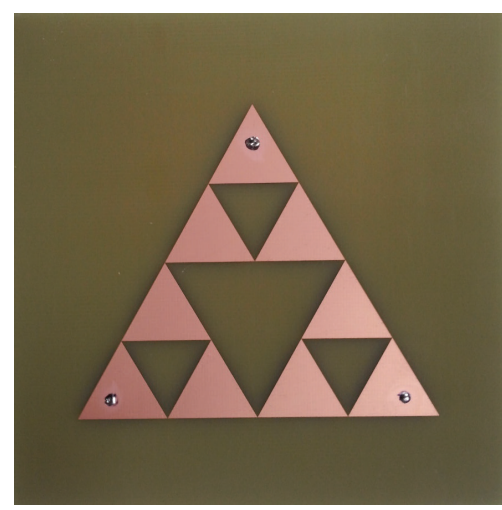

(b)

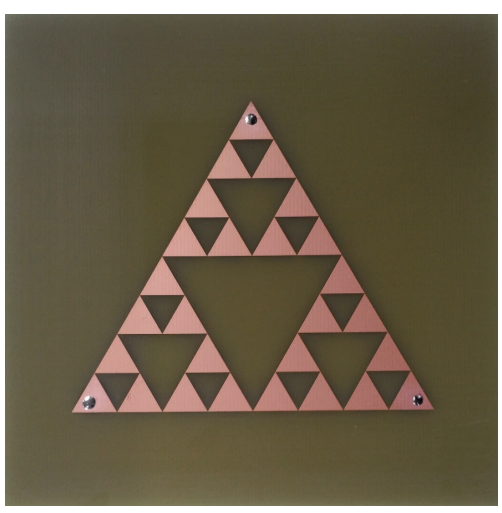

(c)

FIgURE 4: The fabricated antennas at three orders: (a) 1st order, (b) 2nd order, and (c) 3rd order.

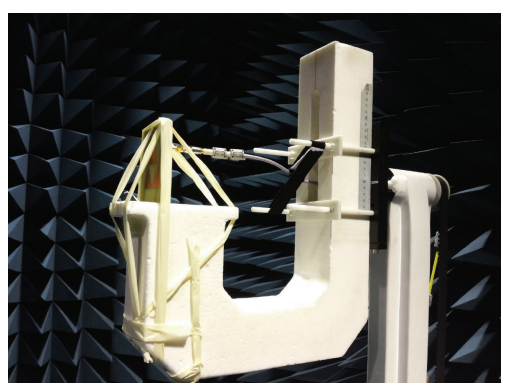

FIGURE 5: Measurement process of radiation patterns in an anechoic chamber.

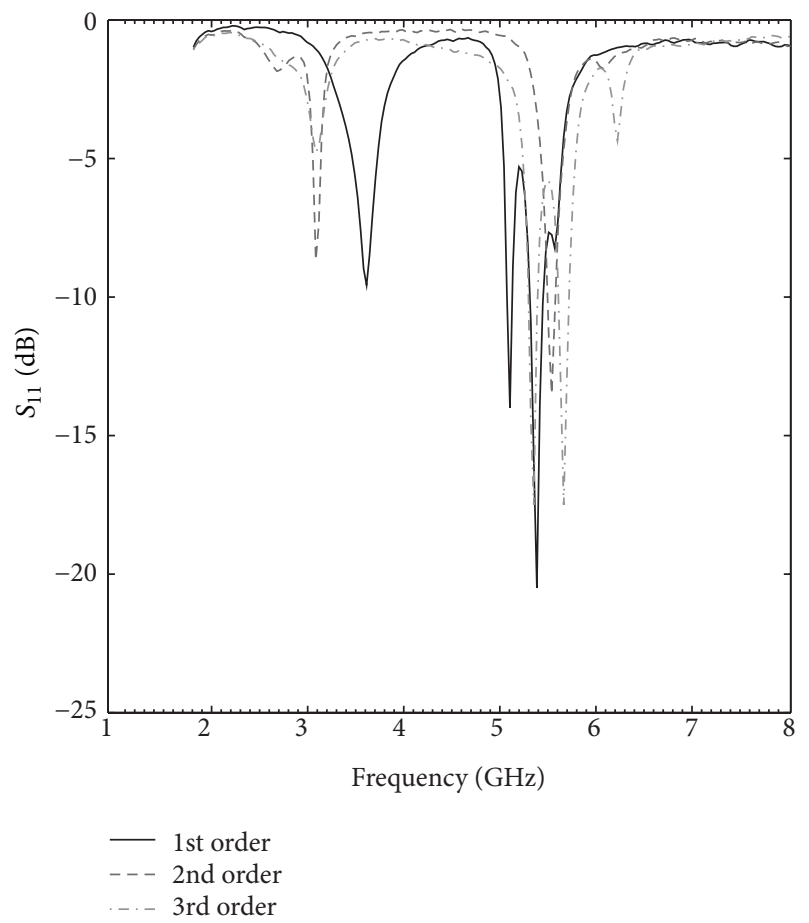

FIGURE 6: Measured reflection coefficients $\left(S_{11}\right)$ of the proposed antennas. of the 1 st order were $-35^{\circ}$ and $35^{\circ}$, those of the 2 nd order were $-30^{\circ}$ and $30^{\circ}$, and those of the 3 rd order were $-40^{\circ}$ and $40^{\circ}$ symmetrically at the second resonance on $y z$ plane $\left(\emptyset=90^{\circ}\right)$. The radiation patterns of the proposed antennas at the first resonant frequencies $(3 \mathrm{GHz}, 2.44 \mathrm{GHz}$, and $2.44 \mathrm{GHz}$ ) in the three orders are similar to those of standard patch antenna. However, at the second resonant frequencies $(5 \mathrm{GHz}, 5.2 \mathrm{GHz}$, and $5.34 \mathrm{GHz}$ ), the radiation patterns are tilted about average $35^{\circ}$ against each feeding point. This characteristic was employed intentionally to tilt the beam according to the change in location of the feeding points. Furthermore, the proposed antennas are easy to fabricate using the Sierpinski triangle. The measured maximum beam direction, peak gain, and HPBW of the proposed antennas are summarized in Table 3. The measurement result for the antennas is in good agreement with the simulated result. Minor differences between the simulated and measured values can be caused by fabrication tolerance and the effect of the feeding cable, which the simulation tool does not take into account for calculating results of $S$-parameter and radiation patterns.

\section{Conclusions}

Dual band and beam-steering antennas using reconfigurable feed on Sierpinski structure have been designed and measured. The proposed fractal antennas are configured with three orders (1st, 2nd, and 3rd). Table 4 shows the comparison of the proposed antenna with other dual band reconfigurable antennas. The proposed antennas are manufactured with well-known fractal structure and are able to have a dual band by using the structure itself without additional components. By changing location of the feeding points without using particular RF switches, the antennas have beamsteering capability. The applicability area of the antenna is communication devices which operate in ISM band and IEEE $802.11 \mathrm{a} / \mathrm{b} / \mathrm{g} / \mathrm{n}$ band. Therefore, it is possible to use it for applications which require enhancing communication 

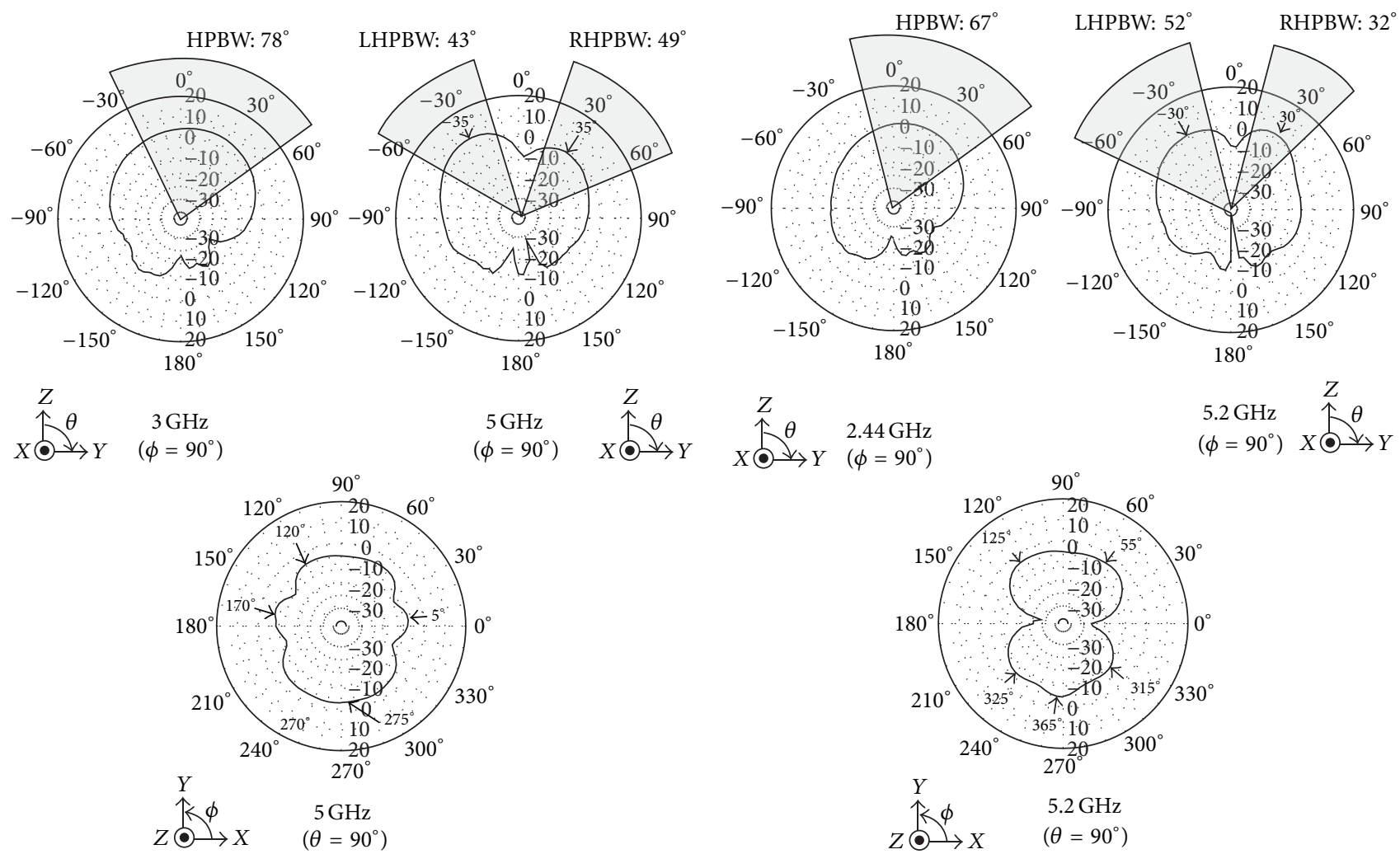

(a)

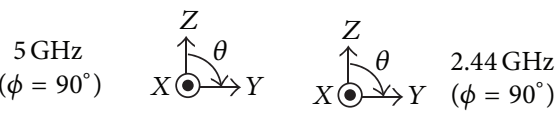
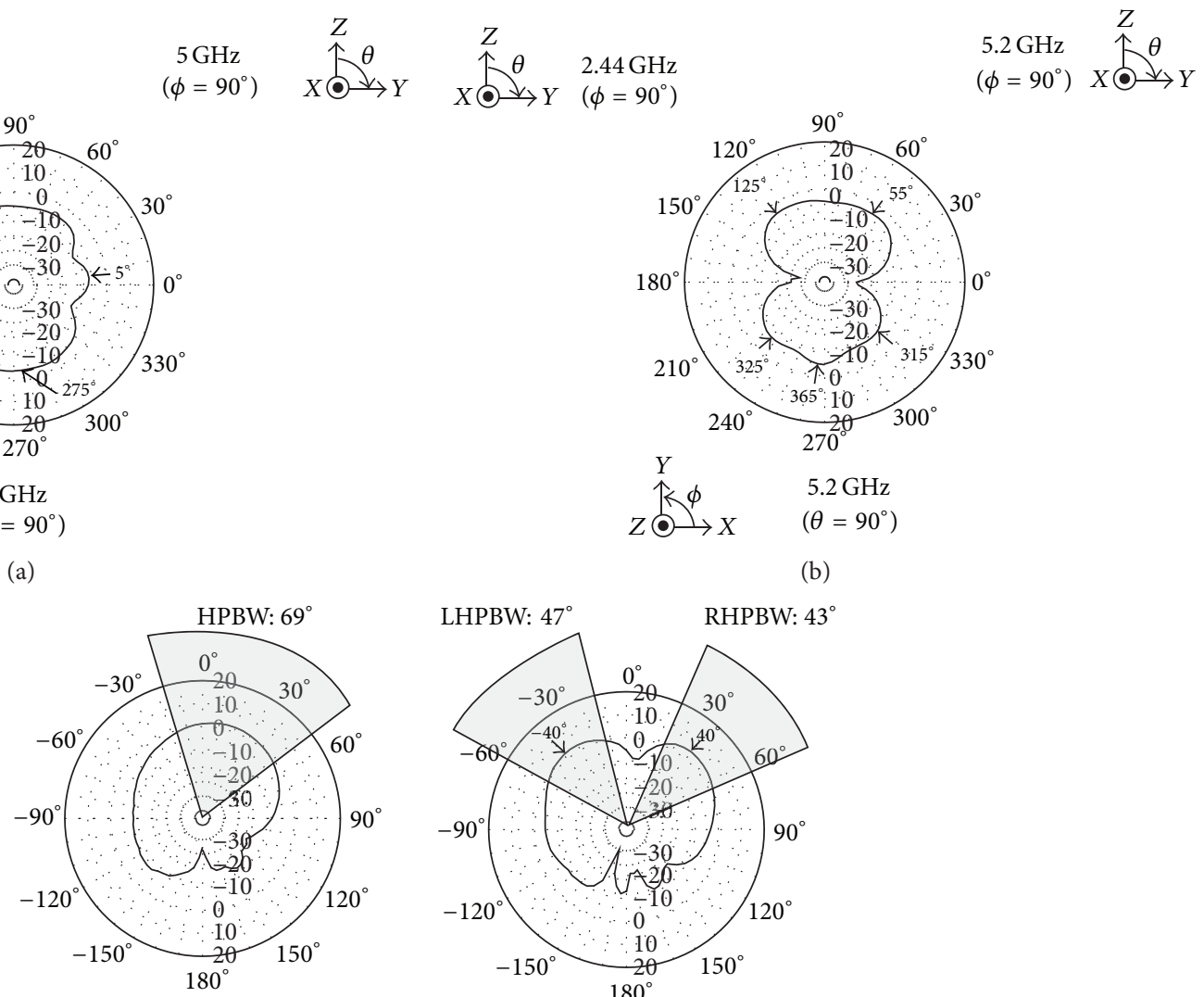

(b)
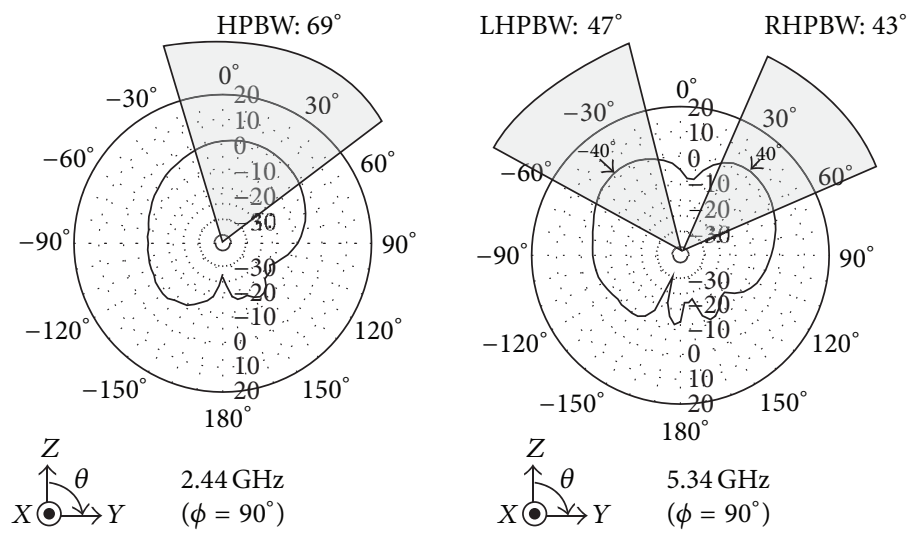

$$
\begin{array}{ll}
{ }^{\theta} & 5.34 \mathrm{GHz} \\
\longrightarrow & \left(\phi=90^{\circ}\right)
\end{array}
$$

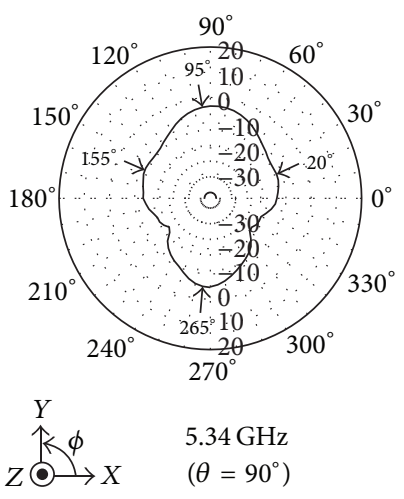

(c)

FiguRE 7: Measured 2D radiation patterns of the proposed antennas: (a) 1st order, (b) 2nd order, and (c) 3rd order. 
TABLE 3: Summary of the measured antennas' performances.

\begin{tabular}{|c|c|c|c|c|c|}
\hline \multirow{2}{*}{ Order } & \multirow{2}{*}{ Resonant frequency } & \multicolumn{2}{|c|}{ Maximum beam direction $\left({ }^{\circ}\right)$} & \multirow{2}{*}{$\operatorname{HPBW}\left({ }^{\circ}\right)$} & \multirow{2}{*}{ Peak gain $(\mathrm{dBi})$} \\
\hline & & $\theta$ & $\emptyset$ & & \\
\hline \multirow{2}{*}{ 1st order } & $3 \mathrm{GHz}$ & - & - & 78 & 5.06 \\
\hline & $5 \mathrm{GHz}$ & $-35,35$ & 275 & (L) 43, (R) 49 & 5.93 \\
\hline \multirow{2}{*}{ 2nd order } & $2.44 \mathrm{GHz}$ & - & - & 67 & 2.38 \\
\hline & $5.2 \mathrm{GHz}$ & $-30,30$ & 55 & (L) 52, (R) 32 & 3.06 \\
\hline \multirow{2}{*}{ 3rd order } & $2.44 \mathrm{GHz}$ & - & - & 69 & 2.14 \\
\hline & $5.34 \mathrm{GHz}$ & $-40,40$ & 95 & (L) $47,(\mathrm{R}) 43$ & 4.07 \\
\hline
\end{tabular}

TABLE 4: Comparison of the proposed antenna with other dual band reconfigurable antennas.

\begin{tabular}{|c|c|c|c|c|}
\hline Reference & $\begin{array}{c}\text { Dimensions } \\
(\mathrm{mm} \times \mathrm{mm} \times \mathrm{mm})\end{array}$ & $\begin{array}{c}\text { Bandwidth } \\
(\mathrm{GHz})\end{array}$ & $\begin{array}{c}\text { Peak gain } \\
(\mathrm{dBi})\end{array}$ & Characteristics \\
\hline$[19]$ & $\begin{array}{c}80 \times 80 \times 3.04 \\
\left(19,456 \mathrm{~mm}^{3}\right)\end{array}$ & $\begin{array}{l}3.72-3.84 \\
4.64-4.76 \\
\end{array}$ & $\begin{array}{l}9.2 \\
9.3 \\
\end{array}$ & 4-feed/2 square-loop \\
\hline$[20]$ & $\begin{array}{c}70 \times 30 \times 0.8 \\
\left(1,680 \mathrm{~mm}^{3}\right) \\
\end{array}$ & $\begin{array}{c}1.56-1.58 \\
2.39-2.5 \\
\end{array}$ & $\begin{array}{l}2.1 \\
2.7 \\
\end{array}$ & Using a folded slot with a branch edge \\
\hline$[21]$ & $\begin{array}{l}\qquad \begin{array}{c}160 \times 170 \\
\left(27,200 \mathrm{~mm}^{2}\right)\end{array} \\
\text { The height was not mentioned. }\end{array}$ & $\begin{array}{l}2.41-2.59 \\
5.56-5.98\end{array}$ & $\begin{array}{l}0.1 \\
0.2\end{array}$ & 4-element array/8 PIN diodes \\
\hline$[22]$ & $\begin{array}{l}60 \times 60 \times 40.8 \\
\left(146,880 \mathrm{~mm}^{3}\right) \\
\end{array}$ & $\begin{array}{l}2.31-2.76 \\
4.92-5.22 \\
\end{array}$ & $\begin{array}{l}3.54 \\
7.77 \\
\end{array}$ & Frequency-selective reflector \\
\hline This work & $\begin{array}{c}100 \times 100 \times 1.6 \\
\left(16,000 \mathrm{~mm}^{3}\right)\end{array}$ & $\begin{array}{l}2.44-3.13 \\
4.67-5.44\end{array}$ & $\begin{array}{l}5.06 \\
5.93\end{array}$ & 3-feed/fractal structure \\
\hline
\end{tabular}

efficiency, such as healthcare systems, industrial fields, and military services.

\section{Conflict of Interests}

The authors declare that there is no conflict of interests regarding the publication of this paper.

\section{Acknowledgments}

This work was supported by the National Research Foundation of Korea (NRF) funded by the Ministry of Education, Science and Technology (NRF-2013R1A1A1A05006118) and in part by the BK21 Plus project by NRF Korea.

\section{References}

[1] J. Anguera, C. Puente, C. Borja, and J. Soler, "Fractal shaped antennas: a review," in Encyclopedia of $R F$ and Microwave Engineering, vol. 2, pp. 1620-1635, Wiley, 2005.

[2] I. K. Kim, N. Kingsley, M. A. Morton et al., "Koch fractal shape microstrip bandpass filters on high resistivity silicon for the suppression of the 2nd harmonic," Journal of Electromagnetic Engineering and Science, vol. 6, no. 4, pp. 235-243, 2006.

[3] L. Li, Z. Wu, K. Li et al., "Frequency-reconfigurable quasisierpinski antenna integrating with dual-band high-impedance surface," IEEE Transactions on Antennas and Propagation, vol. 62, no. 9, pp. 4459-4467, 2014.

[4] M. M. A. Kumar, A. Patnaik, and C. G. Christodoulou, "Design and testing of a multifrequency antenna with a reconfigurable feed," IEEE Antennas and Wireless Propagation Letters, vol. 13, pp. 730-733, 2014.

[5] C. Puente, J. Romeu, R. Pous, X. Garcia, and F. Benitez, "Fractal multiband antenna based on the Sierpinski gasket," Electronics Letters, vol. 32, no. 1, pp. 1-2, 1996.

[6] C. Puente-Baliarda, J. Romeu, R. Pous, and A. Cardama, "On the behavior of the Sierpinski multiband fractal antenna," IEEE Transactions on Antennas and Propagation, vol. 46, no. 4, pp. 517-524, 1998.

[7] B. R. Franciscatto, T.-P. Vuong, and G. Fontgalland, "High gain Sierpinski Gasket fractal shape antenna designed for RFID," in Proceedings of the SBMO/IEEE MTT-S International Microwave \& Optoelectronics Conference (IMOC '11), pp. 239-243, IEEE, Natal, Brazil, October-November 2011.

[8] J. Anguera, E. Martínez, C. Puente, C. Borja, and J. Soler, "Broad-band dual-frequency microstrip patch antenna with modified Sierpinski fractal geometry," IEEE Transactions on Antennas and Propagation, vol. 52, no. 1, pp. 66-73, 2004.

[9] M. Waqas, Z. Ahmed, and M. bin Ihsan, "Multiband Sierpinski fractal antenna," in Proceedings of the IEEE 13th International Multitopic Conference (INMIC '09), pp. 1-6, Islamabad, Pakistan, December 2009.

[10] K. C. Hwang, "A modified sierpinski fractal antenna for multiband application," IEEE Antennas and Wireless Propagation Letters, vol. 6, pp. 357-360, 2007.

[11] R. K. Mishra, R. Ghatak, and D. R. Poddar, "Design formula for sierpinski gasket pre-fractal planar-monopole antennas [antenna designer's notebook]," IEEE Antennas and Propagation Magazine, vol. 50, no. 3, pp. 104-107, 2008.

[12] H. Oraizi and S. Hedayati, "Miniaturization of microstrip antennas by the novel application of the Giuseppe Peano fractal 
geometries," IEEE Transactions on Antennas and Propagation, vol. 60, no. 8, pp. 3559-3567, 2012.

[13] H. Liu, Y. Liu, M. Wei, and S. Gong, "Dual-broadband dielectric resonator antenna based on modified Sierpinski fractal geometry," Electronics Letters, vol. 51, no. 11, pp. 806-808, 2015.

[14] H. Oraizi and S. Hedayati, "Miniaturized UWB monopole microstrip antenna design by the combination of Giusepe Peano and Sierpinski carpet fractals," IEEE Antennas and Wireless Propagation Letters, vol. 10, pp. 67-70, 2011.

[15] C. P. Baliarda, C. B. Borau, M. N. Rodero, and J. R. Robert, "An iterative model for fractal antennas: application to the Sierpinski gasket antenna," IEEE Transactions on Antennas and Propagation, vol. 48, no. 5, pp. 713-719, 2000.

[16] D. Kornek, C. Orlob, and I. Rolfes, "A sierpinski shaped patch antenna for beam switching," in Proceedings of the IEEE International Symposium on Antennas and Propagation and USNC/URSI National Radio Science Meeting (APSURSI '09), 4, p. 1, Charleston, SC, USA, June 2009.

[17] G. Kim and B. Lee, "Metamaterial-based zeroth-order resonant antennas for MIMO applications," Journal of Electromagnetic Engineering and Science, vol. 13, no. 3, pp. 195-197, 2013.

[18] K. Sanda, N. Itoh, N. Suzuki, J. Imai, and K. Ito, "Adaptive beam steering reception system for ISDB-T based on Pre-FFT diversity technique," IEEE Transactions on Consumer Electronics, vol. 52, no. 2, pp. 327-335, 2006.

[19] A. Pal, A. Mehta, D. Mirshekar-Syahkal, P. Deo, and H. Nakano, "Dual-band low-profile capacitively coupled beam-steerable square-loop antenna," IEEE Transactions on Antennas and Propagation, vol. 62, no. 3, pp. 1204-1211, 2014.

[20] C. Hung and T. Chiu, "Dual-band reconfigurable antenna design using slot-line with branch edge," IEEE Transactions on Antennas and Propagation, vol. 63, no. 2, pp. 508-516, 2015.

[21] M. Z. M. Nor, S. K. A. Rahim, M. I. Sabran, P. J. Soh, and G. A. E. Vandenbosch, "Dual-band, switched-beam, reconfigurable antenna for WLAN applications," IEEE Antennas and Wireless Propagation Letters, vol. 12, pp. 1500-1503, 2013.

[22] C.-H. Ko, I.-Y. Tarn, and S.-J. Chung, "A compact dualband pattern diversity antenna by dual-band reconfigurable frequency-selective reflectors with a minimum number of switches," IEEE Transactions on Antennas and Propagation, vol. 61, no. 2, pp. 646-654, 2013. 

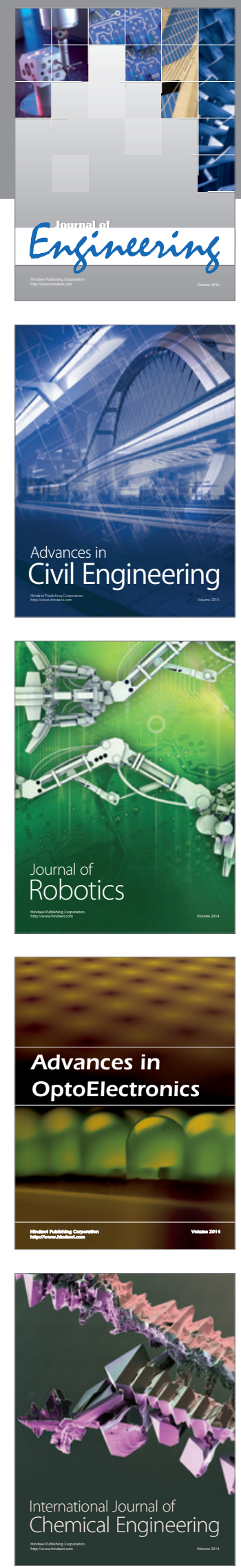

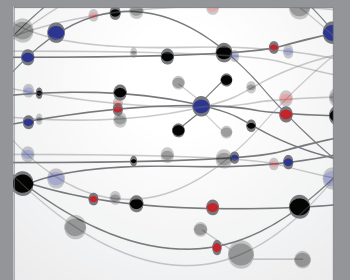

The Scientific World Journal
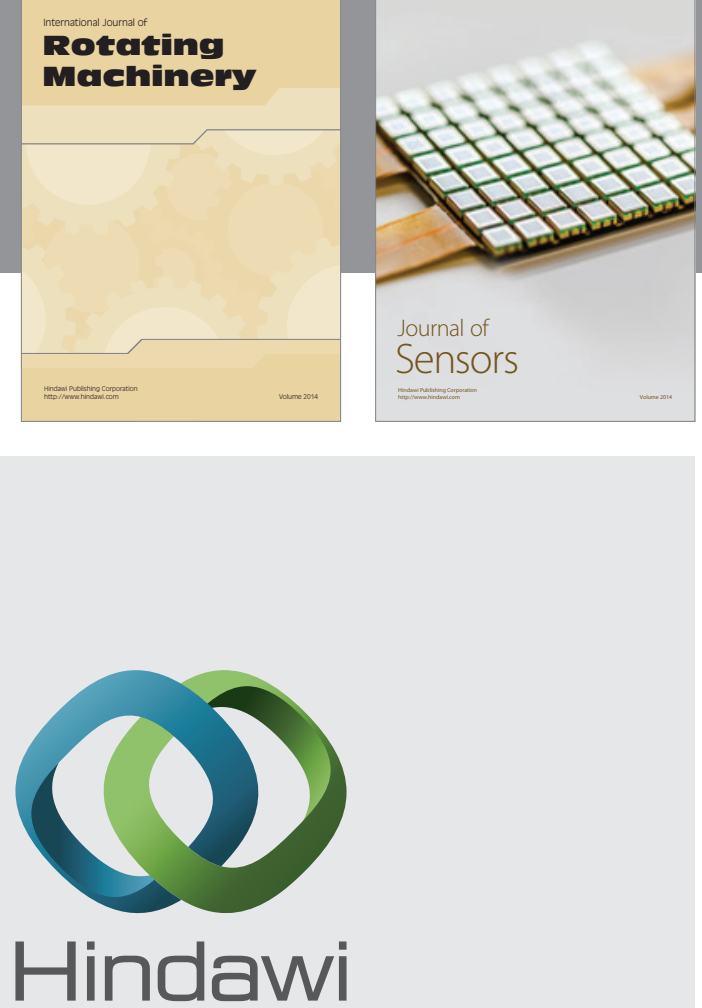

Submit your manuscripts at http://www.hindawi.com
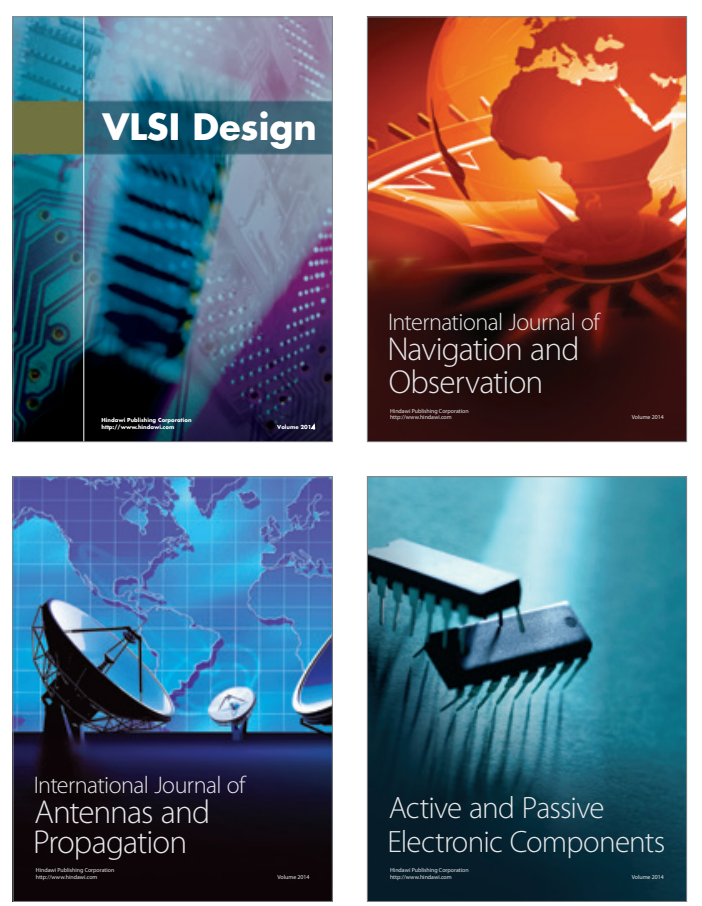
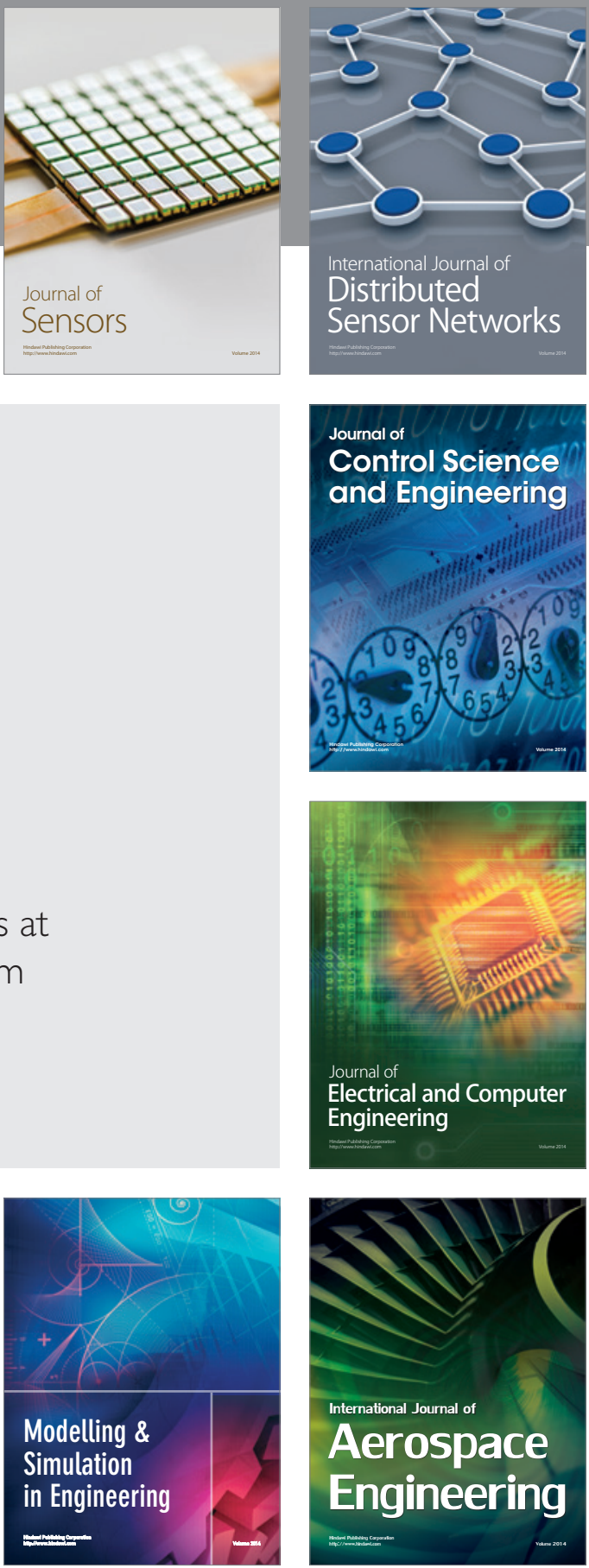

Journal of

Control Science

and Engineering
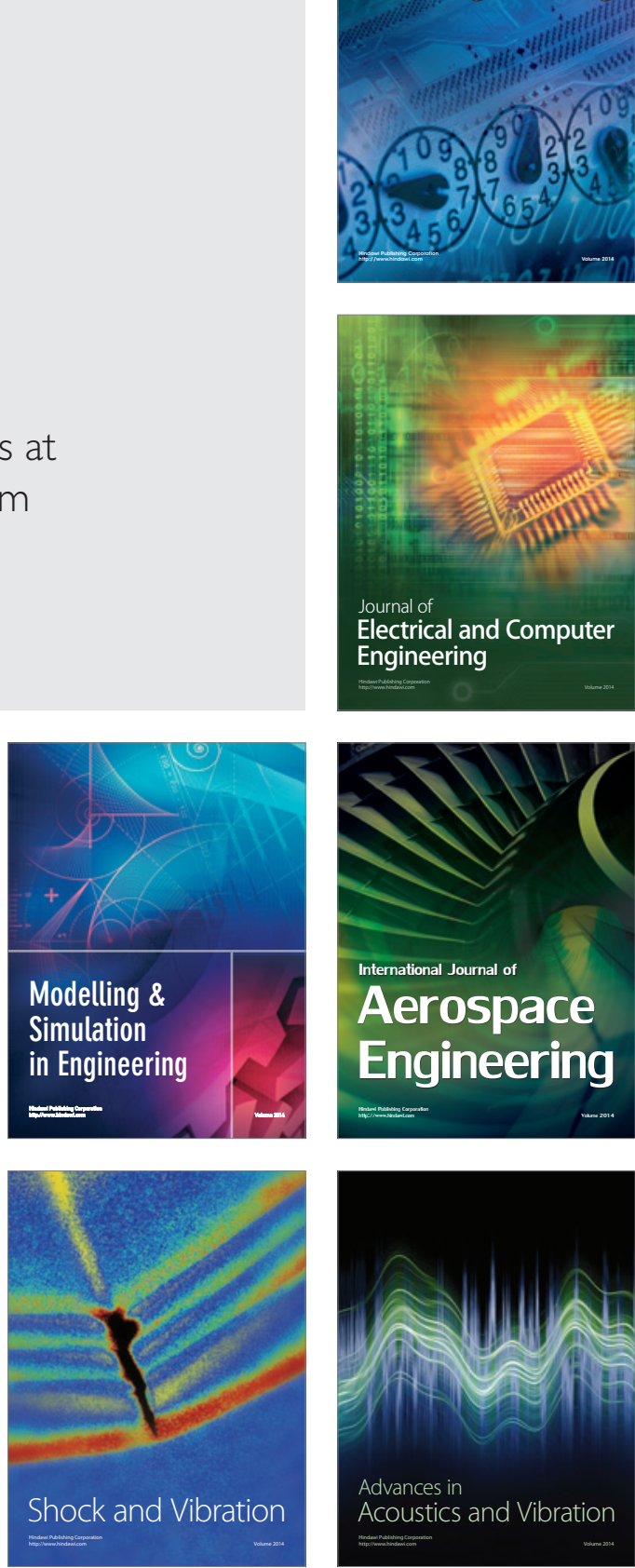